\title{
Nanofibers of gelatin and polivinyl-alcohol-chitosan for wound dressing application: fabrication and characterization
}

\author{
Paola Campa-Siqueiros ${ }^{1}$, Tomás Jesús Madera-Santana ${ }^{1 *}$ (D), Jesús Fernando Ayala-Zavala1, \\ Jaime López-Cervantes ${ }^{2}$, María Mónica Castillo-Ortega ${ }^{3}$ and Pedro Jesús Herrera-Franco ${ }^{4}$ \\ ${ }^{1}$ Coordinación de Tecnología de Alimentos de Origen Vegetal, Centro de Investigación en Alimentación y \\ ²Laboratorio Biotecnología y Ciencias Alimentarias, Instituto Tecnológico de Sonora, Ciudad Obregón, \\ Sonora, México \\ ${ }^{3}$ Laboratorio de Química de Polímeros, Universidad de Sonora, Hermosillo, Sonora, México \\ ${ }^{4}$ Unidad de Materiales, Centro de Investigación Científica de Yucatán, A.C., Mérida, Yucatán, México \\ *madera@ciad.mx
}

\begin{abstract}
Electrospun nanofibers from gelatin (G), chitosan (CS), and chitosan-polyvinyl alcohol (CS-PVA) were developed by electrospinning process. Mechanical properties were determined by the tensile test, the elastic modulus values of the nanofibers were G (15.418-34.34 MPa) and CS-PVA (17.44-126.427 MPa). The morphological characterization by SEM revealed that the systems with $15 \% \mathrm{G}$ and $6 \% \mathrm{CS}$-PVA showed morphological homogeneity. Structural characterization by FTIR indicated an interaction among some functional groups of the component. Thermal analysis by DSC and TGA showed degradation temperatures for $\mathrm{G}\left(330{ }^{\circ} \mathrm{C}\right), \mathrm{CS}\left(210^{\circ} \mathrm{C}\right.$ to $\left.370{ }^{\circ} \mathrm{C}\right)$, and PVA $\left(310{ }^{\circ} \mathrm{C}\right.$ to $\left.420{ }^{\circ} \mathrm{C}\right)$. The contact angles values denoted the hydrophilic nature of the material. Finally, the antimicrobial assay proved that both $15 \% \mathrm{G}$ and 7\% PVA on the CS-PVA system presented the best antimicrobial effect. The results indicate that the electrospun nanofibers fabricated with G or CS-PVA can be used as wound healing dressings.
\end{abstract}

Keywords: chitosan, electrospinning, gelatin, PVA, wound dressing.

How to cite: Campa-Siqueiros, P., Madera-Santana, T. J., Ayala-Zavala, J. F., López-Cervantes, J., Castillo-Ortega, M. M., \& Herrera-Franco, P. J. (2020). Nanofibers of gelatin and polivinyl-alcohol-chitosan for wound dressing application: fabrication and characterization. Polímeros: Ciência e Tecnologia, 30(1), e2020006. https://doi.org/10.1590/01041428.07919

\section{Introduction}

Nowadays, diabetes is the second cause of mortality in México, only $4.5 \%$ less than cardiovascular diseases. This metabolic disease affects glucose levels in blood, increasing them in consequence of a lack of insulin secretion or resistance ${ }^{[1]}$. This prevalence is translated to a considerable economic impact in the country, where the National Health Sector has reported a cost of around 3,400 million dollars for the treatment of diabetes complications, above all, skin wounds ${ }^{[2]}$.

The reason which the health sector manages such a high budget resides on the complexity of the skin wound healing process in a diabetic patient. In comparison to a healthy person, the wound healing process of a diabetic patient is compromised ${ }^{[3]}$, consequence of multiple factors, such as immune system deficiency, poor circulation, metabolic disturbances, propensity of infection and loss of sensation because of neuropathy ${ }^{[1]}$. On tissue injury, a healthy person forms a fibrin plug for either the re-establishment of homeostasis or the aggregation of platelets for the secretion

of growth factors (such as transforming growth factor-beta $(\text { TGF- } \beta)^{[4]}$. Subsequently, these inflammatory cells induce other growth factors, e.g. platelet-derived growth factor (PDFG) amongst others, all of this on the extracellular matrix $(\mathrm{ECM})^{[5]}$. Nevertheless, on a diabetic patient, the expression of these growth and angiogenic factors is impaired, stalling the healing process ${ }^{[5,6]}$.

Different alternatives for diabetic skin ulcer treatment, particularly on the polymeric material field, one of these alternatives is chitosan (CS), it is a natural polymer that has reported promising features for diabetic skin ulcers $^{[6,7]}$, in fact there are some commercial wound dressings based on chitosan (Table 1). As addressed before, CS is a natural biopolymer, obtained by the partial deacetylation of chitin under strong alkaline conditions, formed by $\beta$ (1-4)-D-glucosamine and $\beta(1,4) \mathrm{N}$-acetylD-glucosamine (NAGA) ${ }^{[8]}$. Aside from its antimicrobial, analgesic, antioxidant, and neuroprotective $\mathrm{e}^{[9-11]}$ effects, chitosan has presented an effect upon the wound healing 
Table 1. Commercial chitosan-based wound dressings.

\begin{tabular}{ll}
\hline \multicolumn{1}{c}{ Trademarks } & \multicolumn{1}{c}{ Characteristics } \\
\hline Tegasorb $\mathrm{P}^{\circledR} 3 \mathrm{M}$ & $\begin{array}{l}\text { Gel. Contains chitosan particles that swell } \\
\text { while absorbing exudate and forms the gel. }\end{array}$ \\
Chitoflex ${ }^{\circledR}$ HemCom & $\begin{array}{l}\text { Gel. Seals and stabilizes the sound } \\
\text { Cotton-like chitosan gel. Rebuilds body and } \\
\text { Chitopack C }{ }^{\circledR} \text { Eisai }\end{array}$ \\
\hline
\end{tabular}

Modified from Liu et al. ${ }^{[3]}$.

process $^{[3]}$, specifically on its effect of enhancing growth factor release ${ }^{[10,12,13]}$. However, most of the reports of the chitosan effect upon wound healing of diabetic patients are based on gels, with the disadvantage that the treatment must be applied by a professional as well as quite often.

From different ways for chitosan processing, electrospinning for the obtaining of nanofibers is a way to surpass the previously mentioned gel disadvantages. These ultrafine continuous fibers are the product of high electric potentials ${ }^{[14]}$. Apart from being a versatile (a great number of polymers can be processed), simple and the rather cheap process $^{[15]}$, electrospun nanofibers possess a couple of properties which give them a great spectra of applications on biomedical materials: high surface area to volume ratio (which translates on oxygen permeability, fluid exchange without accumulation and uniform adherence in situ $\left.{ }^{[16]}\right)$ accompanied with high porosity at the various pore size ${ }^{[15]}$. There are reports of their application as scaffolds for different tissue regeneration $^{[17]}$, cartilage ${ }^{[18]}$, bone $e^{[19]}$, drug delivery ${ }^{[20]}$ and, as the type of material of interest in the present work, wound dressings ${ }^{[9]}$. This particular application is possible because of the nanofibers' structural capacity to attract the appropriate cellular growth substrates ${ }^{[21]}$. As the principal barrier of protection for the wound, the scaffolds for wound dressing application have met some important criteria: They should facilitate gas permeation, present a controlled adhesion to the wound, as well as durability, flexibility and is capable of absorbing the wound exudates ${ }^{[22]}$. Even though electrospun chitosan nanofibers possess many desirable characteristics, the electrospinning process for chitosan tends to be difficult, being that chitosan is polycationic and electrospinning principle is passed on charge application ${ }^{[8]}$. Therefore, to process chitosan by electrospinning it requires the incorporation of other material to enable the process (electrospinning agent).

There are numerous electrospinning agents for chitosan, either natural or synthetic polymers. A natural polymeric alternative is a gelatin $(\mathrm{G})$. This protein is prepared by collagen hydrolysis ${ }^{[23]}$, resulting in a structure consisting of mainly hydroxyproline, glycine, and proline amino acids ${ }^{[24]}$. Aside from being biodegradable and electrospinning compatible, gelatin has the important characteristic of being affordable and giving electrospun fibers with controllable thickness and physical stability ${ }^{[25]}$. On the other hand, some examples of synthetic biopolymers are polyethylene oxide (PEO) ${ }^{[26]}$, collagen $^{[27]}$, and polycaprolactone (PCL) ${ }^{[28]}$. However, all the previously mentioned electrospinning agents present disadvantages, such as the need for a crosslinking agent, difficult processing, and pearling formation. Another electrospinning agent for chitosan is polyvinyl alcohol (PVA) which is a non-toxic and water-soluble synthetic biopolymer ${ }^{[29]}$, it has been reported a significant improvement on the mechanical properties of chitosan electrospun nanofibers ${ }^{[30]}$.

The aim of this study is to fabricate electrospun gelatin and chitosan-PVA nanofibers and evaluate their physicochemical properties (optical, mechanical, structural, thermal and morphological). An antimicrobial analysis was performed in order to explore the potential of the biomaterials produced for a possible application as wound dressings.

\section{Materials and Methods}

\subsection{Materials}

Gelatin (type B), medium weight chitosan with 75 to $85 \%$ deacetylated grade, and polyvinyl alcohol (PVA) (high Mw) were purchased from Sigma Aldrich, (St. Louis, Missouri, USA). Glacial acetic acid (GAA), CAS [64-19-7] with $2.5 \mathrm{pH}$ and a density of $1.05 \mathrm{~g} / \mathrm{cm}^{3}$ was obtained from Fagalab, MEX.

\subsection{Preparation of G, CS, PVA and CS-PVA solutions}

G solution was prepared following the method described by Okutan et al. ${ }^{[31]}$ with some modifications. The gelatin was dissolved in acetic acid solution $(20 \% \mathrm{w} / \mathrm{v})$ at 15 and $20 \% \mathrm{w} / \mathrm{v}$. Solutions were stirred for $4 \mathrm{~h}$, at $40{ }^{\circ} \mathrm{C}$ and $900 \mathrm{rpm}$ on a magnetic stirrer until a clear and homogenous blend. CS solution was prepared at $1 \% \mathrm{w} / \mathrm{v}$ with the GAA and MiliQ water at 1:1 relation. The solution was stirred for $24 \mathrm{~h}$ at $25^{\circ} \mathrm{C}$. PVA solutions of $6 \%, 7 \%$, and $8 \% \mathrm{w} / \mathrm{v}$ were prepared with MiliQ water as a solvent and were stirred at $900 \mathrm{rpm}$ and $80^{\circ} \mathrm{C}$ for $4 \mathrm{~h}$. The CS-PVA solution was stirred at $900 \mathrm{rpm}$, $25^{\circ} \mathrm{C}$ for $3 \mathrm{~h}$ at $1: 1$ relation.

\subsection{Fabrication of $G$ and CS-PVA nanofibers}

The electrospinning process was carried at room temperature on a system composed as follows: A dual syringe infusion withdrawal pump (KDS 2010, KDScientific, Holliston, USA), a high voltage power supply (CZE1000R, Spellman, USA), the tip of the needle where the voltage was applied and an aluminum collector. Table 2 shows the sample number and the biopolymer used gelatin $(\mathrm{G})$ or polyvinyl alcohol (PVA), as well as, the electrospinning conditions for G and CS-PVA. It is important to point out that in the case of CS-PVA solutions, CS \% was a constant $1 \% \mathrm{w} / \mathrm{v}$. PVA percentages were chosen based on their best morphological characteristics. Whereas CS percentage was the only one that could form nanofibers at the moment of electrospinning.

\subsection{Characterization of $G$ and CS-PVA nanofibers}

\subsubsection{Thickness}

The thickness of the G and CS-PVA nanofibers were measured with a digital micrometer (Mitutoyo MDC -1"PX, Kawasaki-Shi, Kamagaya, Japan). To obtain the average thickness of the nanofibers, five measurements were performed, one measure on each corner and one in the middle of the resultant square nanofiber membranes. 
Table 2. Formulations and electrospinning conditions of G and CS:PVA solutions.

\begin{tabular}{|c|c|c|c|c|c|c|c|}
\hline Sample & $\begin{array}{c}G \\
(\%)\end{array}$ & $\begin{array}{l}\mathrm{CS} \\
(\%)\end{array}$ & $\begin{array}{l}\text { PVA } \\
(\%)\end{array}$ & $\begin{array}{c}\text { Collector } \\
\text { distance }(\mathrm{cm})\end{array}$ & $\begin{array}{c}\text { Injection rate } \\
(\mathrm{mL} / \mathrm{h})\end{array}$ & $\begin{array}{c}\text { Voltage } \\
\text { (Kv) }\end{array}$ & $\begin{array}{c}\text { Needle caliber } \\
\text { (g) }\end{array}$ \\
\hline 1 & 15 & - & - & 10 & 1 & -17 & 23 \\
\hline 2 & 20 & - & - & 10 & 1 & 15 & 23 \\
\hline 3 & - & 1 & 6 & 10 & 1 & 17 & 22 \\
\hline 4 & - & 1 & 6 & 15 & 1 & 24 & 22 \\
\hline 5 & - & 1 & 7 & 15 & 1 & 21 & 22 \\
\hline 6 & - & 1 & 7 & 15 & 1 & 20 & 23 \\
\hline 7 & - & 1 & 8 & 15 & 2 & 25 & 20 \\
\hline 8 & - & 1 & 8 & 15 & 2 & 22 & 18 \\
\hline
\end{tabular}

\subsection{Color}

The nanofibers color was evaluated with a colorimeter (Minolta CR-300, Osaka, Japan), calibrated with a standard $(Y=94.1, x=0.3155$, and $y=0.3319)$. Each nanofiber membrane was measured 5 times. The color change $(\Delta \mathrm{E})$, chromaticity $\left(C^{*}\right)$, and Hue angle $\left(H^{*}\right)$ were measured with Equations 1, 2, and 3, respectively.

$$
\begin{aligned}
& \Delta E=\sqrt{\left(\Delta L^{*}\right)^{2}+\left(\Delta a^{*}\right)^{2}+\left(\Delta b^{*}\right)^{2}} \\
& C^{*}=\sqrt{a^{* 2}+b^{* 2}} \\
& H^{*}=\operatorname{artg}\left(\frac{b^{*}}{a^{*}}\right)
\end{aligned}
$$

where $L^{*}$ is luminosity; $a^{*}$ is red/green coordinates; and $b^{*}$ yellow/blue coordinates.

\subsection{Tensile strength properties}

The mechanical analysis of the nanofiber's membranes was measured using an universal tensile unit Shimadzu (AGS-X Kyoto, Japan) following the ASTM D1708. Rectangular membrane samples were cut with the following dimensions $5 \mathrm{~mm}$ wide and $24 \mathrm{~mm}$ long, the thickness of each membrane was measured in triplicate. Between 5 and 10 probes for each treatment were measured. The mechanical parameters, such as elastic modulus (EM), tensile strength (TS), and elongation at break (Eb) were calculated from the tensile test, the sample was clamped at the ends of the jaws of the equipment. The separation between clamps was $12 \mathrm{~mm}, 6 \mathrm{~mm}$ of headspace, at a head speed of $10 \mathrm{~mm} / \mathrm{min}$, and the load cell of $100 \mathrm{~N}$ was used for force measurements.

\subsection{Morphological properties}

Morphological properties of the electrospun nanofibers were evaluated by scanning electron microscopy (SEM), using a JEOL (JSM 3000, Akishima, Tokio) with a previous sample coating of $\mathrm{Au} / \mathrm{Pd}$ using a Quorum QI5OR. For better understanding, the sample number was delimited to 6 samples, 2 per PVA percentage, each one with different electrospinning conditions and one of $15 \%$ and $20 \%$ of gelatin each. A morphological analysis of the micromechanical tension samples was focused on the fracture surfaces. In this case, an environmental scanning electron microscope (ESEM) FEI-Philips model XL30 ESEM (Tokio, Japan) was used, with a voltage of $20 \mathrm{kV}$ and magnifications of $500 \mathrm{X}$, $10000 \mathrm{X}$, and 25000X.

\subsection{Structural properties}

Structural properties were characterized by Fourier Transform Infrared-Attenuated Total Reflectance (FTIR-ATR) spectroscopy (Thermo Scientific, with Nicolet iS5 with ATR, Waltham, USA) with a resolution of $4 \mathrm{~cm}^{-1}$ between 4000 and $400 \mathrm{~cm}^{-1}$.

\subsection{Thermal properties}

The thermal properties were analyzed by differential scanning calorimeter (DSC) and thermogravimetric analysis (TGA). DSC analysis was performed using DSC from TA Instruments Inc. (Discovery Series, Delaware, USA) measurements were carried out under a nitrogen flow. Around $5 \mathrm{mg}$ of sample was placed into aluminum cell and sealed, and an empty cell was used as reference. Once that the two cells were ready, these were placed inside the equipment, and heated at $10^{\circ} \mathrm{C} / \mathrm{min}$ from $25^{\circ} \mathrm{C}$ to $300{ }^{\circ} \mathrm{C}$. TGA analysis was carried out on a thermogravimetric analyzer (TGA 8000 PerkinElmer Inc., Massachusetts, U.S.A.), the temperature range was from $24^{\circ} \mathrm{C}$ to $700{ }^{\circ} \mathrm{C}$, at a heating rate of $10^{\circ} \mathrm{C} / \mathrm{min}$. This analysis was used to record the decomposition temperature of the nanofiber materials.

\subsection{Surface hydrophilicity}

The contact angle is a water contact angle of CS-PVA electrospun nanofibers was determined by Contact Angle Meter (CAM-Plus, ChemInstruments, Fairfield, USA). Ten measurements per PVA percentage and each membrane were taken. The droplet of water on a flat nanofiber (solid surface), the balance on the three-phase interface is expressed by Young's equation:

$$
\gamma_{s}=\gamma_{s l}+\gamma_{l} \cos \theta
$$

where the surface tension is $\gamma_{L}$, the contact angle between the interface liquid-air is $\theta$, the interfacial tension $\gamma_{S L}$, and surface free energy of a solid is $\gamma_{S}$.

The sum of the interfacial tensions is given by $\gamma_{S L}$ minus the work of adhesion, the work of adhesion can be expressed as: 


$$
W_{A}=\gamma_{l}(1+\cos \theta)
$$

\subsection{Antimicrobial analysis}

The nanofibers of G and CS-PVA were tested in their antimicrobial properties using a qualitative methodology reported by Ruiz-Ruiz et al. ${ }^{[32]}$ with some modifications. Müller-Hinton agar was inoculated with S. tiphy or S. aureus at $1 \times 10^{8} \mathrm{UFC}$ and incubated at $37^{\circ} \mathrm{C}$ for $12 \mathrm{~h}$. Samples of $1.5 \mathrm{~cm}^{2}$ were deposited on the surface of the culture and incubated at $37^{\circ} \mathrm{C}$ for $8 \mathrm{~h}$. A paper disk with ciprofloxacin was considered as control. Photographs of the resultant Petri dishes were taken by the imaging system Gel Doc ${ }^{\mathrm{TM}}$ (EZ system, BIO-RAD, Hercules, USA).

\subsection{Statistical analysis}

Statistical analyses of mechanical, optical, and contact angle characterization were processed by NCSS ver. 7 software (Kaysville, U.S.A). Data were presented by its mean \pm standard deviation, at a significance level of $\mathrm{P}<0.05$. If a significant difference was observed a mean comparison by Tukey-Kramer was processed.

\section{Results and Discussions}

\subsection{Color}

The color parameters $\Delta \mathrm{E}, C^{*}$, and $H^{*}$ of the samples are presented in Table 3. In the case of $\Delta \mathrm{E}$, the behavior of the samples showed changes between those of $\mathrm{G}$ and CS-PVA. Samples 1 and $2(\mathrm{G})$ showed higher $\Delta \mathrm{E}$ values in comparison to samples 3 to 8 (CS-PVA). This behavior can be explained

Table 3. Optical properties of color of G and CS-PVA nanofibers.

\begin{tabular}{cccc}
\hline Sample & $\boldsymbol{\Delta E}$ & $\boldsymbol{C}^{*}$ & $\boldsymbol{H}^{*}$ \\
\hline 1 & $3.40 \pm 0.17^{\mathrm{c}}$ & $1.33 \pm 0.20^{\mathrm{e}}$ & $66.23 \pm 2.01^{\mathrm{d}}$ \\
2 & $2.02 \pm 0.20^{\mathrm{b}}$ & $1.03 \pm 0.08^{\mathrm{e}}$ & $82.38 \pm 1.87^{\mathrm{d}}$ \\
3 & $1.19 \pm 0.41^{\mathrm{ab}}$ & $1.36 \pm 0.39^{\mathrm{ab}}$ & $53.56 \pm 3.77^{\mathrm{b}}$ \\
4 & $1.42 \pm 0.05^{\mathrm{ab}}$ & $1.33 \pm 0.22^{\mathrm{ab}}$ & $49.14 \pm 6.33^{\mathrm{bc}}$ \\
5 & $0.68 \pm 0.17^{\mathrm{a}}$ & $1.68 \pm 0.74^{\mathrm{a}}$ & $61.16 \pm 1.24^{\mathrm{a}}$ \\
6 & $1.75 \pm 0.10^{\mathrm{b}}$ & $1.06 \pm 0.18^{\mathrm{bc}}$ & $61.33 \pm 0.99^{\mathrm{c}}$ \\
7 & $1.28 \pm 0.44^{\mathrm{ab}}$ & $2.03 \pm 0.31^{\mathrm{ab}}$ & $78.70 \pm 1.45^{\mathrm{bc}}$ \\
8 & $1.88 \pm 0.12^{\mathrm{b}}$ & $1.92 \pm 0.32^{\mathrm{cd}}$ & $76.24 \pm 0.82^{\mathrm{c}}$ \\
\hline
\end{tabular}

Data is presented as mean \pm standard deviation. Abbreviation signification is follows: $\Delta \mathrm{E}$ color difference, $C^{*}$ chromaticity, and $H^{*}$ Hue angle. with the reported by Horsfall ${ }^{[33]}$, the author concluded that the color change observed in the material is produced by the chemical composition of itself. The $\Delta \mathrm{E}$ values for samples with gelatin revealed that the chemical composition would be strongly depended with the gelatin content in the samples, therefore a significant difference was found between them $(\mathrm{P}<0.05)$. However, this behavior becomes to be more complex in the case of the CS-PVA samples. Samples 5 and 6 are significantly different $(\mathrm{P}<0.05)$, even though they belong to the same PVA percentage. However, they differ in morphology, meanwhile sample 5 was fabricated with a needle caliber of $22 \mathrm{~g}$, which has a higher diameter $(0.7 \mathrm{~mm})$ than the needle used on sample 6 which is caliber of $23 \mathrm{~g}$ and $0.6 \mathrm{~mm}$ of diameter. This effect can also be seen between samples 7 and 8 .

Chromaticity can be defined as the color saturation. When a sample presents a low $C^{*}$ value, it infers that they present a high interference of colors, whereas a $C^{*}$ value of 0 means that the samples show an achromatic stimulus ${ }^{[34]}$. The achromatic stimuli addressed previously represented itself by the visually white color of all the samples obtained. In contrast to $\Delta \mathrm{E}$ values, samples 1 and 2 did not show chromatic differences between them, although these showed significant difference $(\mathrm{P}<0.05)$ with samples formulated with CS-PVA.

From previous optical parameters, $H^{*}$ is the most outwardly explaining. This parameter indicates the color of the sample within the color sphere, where tones are represented with the grades within the sphere. Being $90^{\circ}$ represents yellow, $180^{\circ}$ green, $270^{\circ}$ blue and $360^{\circ}$, as well as $0^{\circ}$, represent $\operatorname{red}^{[35]}$. According to Table 3, the samples were between $49.14^{\circ}$ and $82.38^{\circ}$. This, along with a luminosity of average of 95 (data not shown) and the $C^{*}$ obtained, the samples presented a light color, in the yellow region, therefore, the whiteness present visually on all the samples.

\subsection{Thickness}

The thickness of G and CS-PVA nanofibers membranes are presented in Table 4, the values of these systems were found in the range from 0.219 to $0.297 \mathrm{~nm}$ and from 0.015 to $0.57 \mathrm{~nm}$, respectively. The nanofibers of CS-PVA (samples 3 to 8) were obtained at different electrospinning conditions (Table 2), nevertheless, the thickness of these samples did not show significant differences $(\mathrm{P}>0.05)$ as it can be observed in Table 4. Although the electrospinning conditions experimented in this work were different, these allowed the fabrication of nanofibers at different percentages

Table 4. Thickness and tensile at strength properties of G and CS-PVA nanofibers.

\begin{tabular}{|c|c|c|c|c|}
\hline Sample & Thickness (mm) & EM (MPa) & TS (MPa) & $\mathrm{E}(\%)$ \\
\hline 1 & $0.219 \pm 0.05^{b}$ & $34.342 \pm 5.3^{b, c, d}$ & $1.052 \pm 0.318^{b, d}$ & $4.178 \pm 1.354^{\mathrm{a}}$, \\
\hline 2 & $0.297 \pm 0.073^{b}$ & $15.418 \pm 2.205^{\mathrm{b}, \mathrm{d}}$ & $0.409 \pm 0.215^{\mathrm{b}, \mathrm{d}}$ & $4.344 \pm 1.679^{\mathrm{a} c \mathrm{c}}$ \\
\hline 3 & $0.057 \pm 0.014^{a}$ & $\mathrm{NA}^{\mathrm{a}}$ & $14.89 \pm 1.726^{\mathrm{a}}$ & $16.202 \pm 1.56^{\mathrm{a}}$ \\
\hline 4 & $0.032 \pm 0.042^{a}$ & $\mathrm{NA}^{\mathrm{b}}$ & $4.378 \pm 3.063^{b, d}$ & $16.852 \pm 8.266^{\mathrm{a}}$ \\
\hline 5 & $0.023 \pm 0.003^{a}$ & $116.49 \pm 12.599^{\mathrm{b}, \mathrm{c}}$ & $8.269 \pm 2.252^{\mathrm{a}, \mathrm{b}, \mathrm{c}}$ & $15.818 \pm 5.693^{\mathrm{a}}$ \\
\hline 6 & $0.035 \pm 0.007^{a}$ & $17.444 \pm 2.948^{\mathrm{b}, \mathrm{c}, \mathrm{d}}$ & $4.237 \pm 2.581^{\mathrm{b}, \mathrm{d}}$ & $27.674 \pm 9.698^{a, b}$ \\
\hline 7 & $0.024 \pm 0.0005^{\mathrm{a}}$ & $29.201 \pm 6.225^{\mathrm{b}, \mathrm{c}, \mathrm{d}}$ & $5.984 \pm 3.426^{\mathrm{b}, \mathrm{d}}$ & $23.155 \pm 8.281^{a}$, \\
\hline 8 & $0.015 \pm 0^{\mathrm{a}}$ & $126.427 \pm 20.40^{\mathrm{b}, \mathrm{c}, \mathrm{d}}$ & $14.310 \pm 5.047^{\mathrm{a}, \mathrm{c}}$ & $26.502 \pm 9.442 \mathrm{a} \mathrm{b}$ \\
\hline
\end{tabular}

Data is presented as mean \pm standard deviation. Different letters on each column indicate significant differences $(\mathrm{P}<0.05)$. Abbreviation signification is follows: EM: Elastic modulus; TS: Tensile strength; E: Elongation at brake. 
of PVA. However, a significant difference was found between $\mathrm{G}$ and CS-PVA nanofibers, where $\mathrm{G}$ presented the highest values, a consequence of the different electrospinning conditions, added to the nature of the material, in this case, $\mathrm{G}$ can produce nanofiber with higher thickness. It is attributed that gelatin has the most complex and larger structure (formed by proteins, mineral salts, and water), samples 1 and 2 showed the higher nanofiber diameter with 111.66 and $286.33 \mathrm{~nm}$ (Table 5), respectively. It is difficult to compare our values with the literature because the references did not report the values and conditions that the nanofibers are produced.

\subsection{Mechanical properties}

The values of mechanical parameters (elastic modulus, tensile strength, and elongation at brake) for all the samples tested are presented in Table 4. As we can be observed, the samples 3 and 4 have not reported the EM data, as well as they present the higher standard deviation among all the samples. It is related to physical aspect of the material instead of the chemical nature. $G$ nanofibers showed the lowest values in tensile strength and elongation at break, although these samples did not showed significant difference $(p>0.05)$ between them. The tensile strength values of samples of CS-PVA nanofibers is very fluctuating, it is attributed to

Table 5. Nanofiber diameter and general morphological characteristics of $\mathrm{G}$ and CS-PVA nanofibers.

\begin{tabular}{|c|c|c|}
\hline Sample & $\begin{array}{l}\text { Fiber diameter } \\
(\mathbf{n m})\end{array}$ & $\begin{array}{c}\text { General morphological } \\
\text { characteristics }\end{array}$ \\
\hline 1 & $111.66 \pm 7.57^{\mathrm{a}}$ & Fibrillar formation, no drops or fractures. \\
\hline 2 & $286.33 \pm 2.3^{b}$ & Fibrillar formation, no drops or fractures. \\
\hline 3 & $33 \pm 2.5^{c}$ & Fibrillar formation, drops and fiber fracture \\
\hline 4 & $33 \pm 2.5$ & $\begin{array}{l}\text { Fibrillar formation with fractures and } \\
\text { pearling }\end{array}$ \\
\hline 5 & $17.8 \pm 0.9^{d}$ & $\begin{array}{l}\text { Fibrillar formation, pearling, sparse } \\
\text { fiber fracture }\end{array}$ \\
\hline 6 & $17.8 \pm 0.9$ & Fibrillar formation and sparse fiber fracture \\
\hline 7 & $27.8 \pm 1.06^{\mathrm{e}}$ & Fibrillar formation, drops and fiber fracture \\
\hline 8 & $27.8 \pm 1.06^{\mathrm{e}}$ & Fibrillar formation, drops and fiber fracture \\
\hline
\end{tabular}

Data are mean \pm standard deviation $(n=10)$. Significant difference $(\mathrm{P}<0.05)$. sample's thickness which is highly irregular (based on standard deviation). The elongation is a mechanical parameter that it is not related to the thickness. The elongation at break of CS-PVA samples increases as the PVA content is increased. Due to the thickness of the materials, it is difficult to compare these results with literature, since there is no information available (as far as the present authors know).

\subsection{SEM analysis}

SEM micrographs at $50000 \mathrm{X}$ of magnification of the electrospun CS:PVA nanofibers are presented on Figure 1, with their fiber diameter and general morphological characteristics presented on Table 5 .

The samples of $\mathrm{G}$ had the highest fiber diameter value of $286.33 \mathrm{~nm}$ for $20 \% \mathrm{G}$, followed by $15 \% \mathrm{G}$ with $111.66 \mathrm{~nm}$. These results seem coherent since, as explained before, gelatin is a larger molecule. Also, G nanofibers of both concentrations ( $15 \%$ and $20 \% \mathrm{w} / \mathrm{v})$ present the best morphological characteristics of all the materials since they do not present any drops or fractures. The last characteristics can be also observed in Figure 1a and 1b. In comparison with other studies ${ }^{[36]}$, the morphology of $G$ nanofibers in the present study is also more homogeneous than gelatin nanofibers obtained in other studies ${ }^{[31]}$. Following this comparison, it can be observed that gelatin concentration and voltage used in the electrospinning process were two times higher in the previous study than the used in the present study.

Samples 3 and 4 (6\% PVA) showed small morphological improvement since fibrillar formation was observed, although they still presented fracture, pealing and drops. However, samples 5 and 6 presented the best morphological characteristics, since apart from fibrillar formation, they presented sparse fiber fracture, especially sample 6, which in comparison with sample 5, did not present pearling. Nevertheless, Samples 7 and 8 presented undesirable morphological characteristics again, with drops and fiber fracture, as well as an increase of the fiber diameter. The proportional increase in the nanofibers diameter has been reported by Tarus et al. ${ }^{[37]}$. These authors reported the same effect on cellulose acetate nanofibers with a solvent system of acetone/dimethyl acetamide, where the diameter

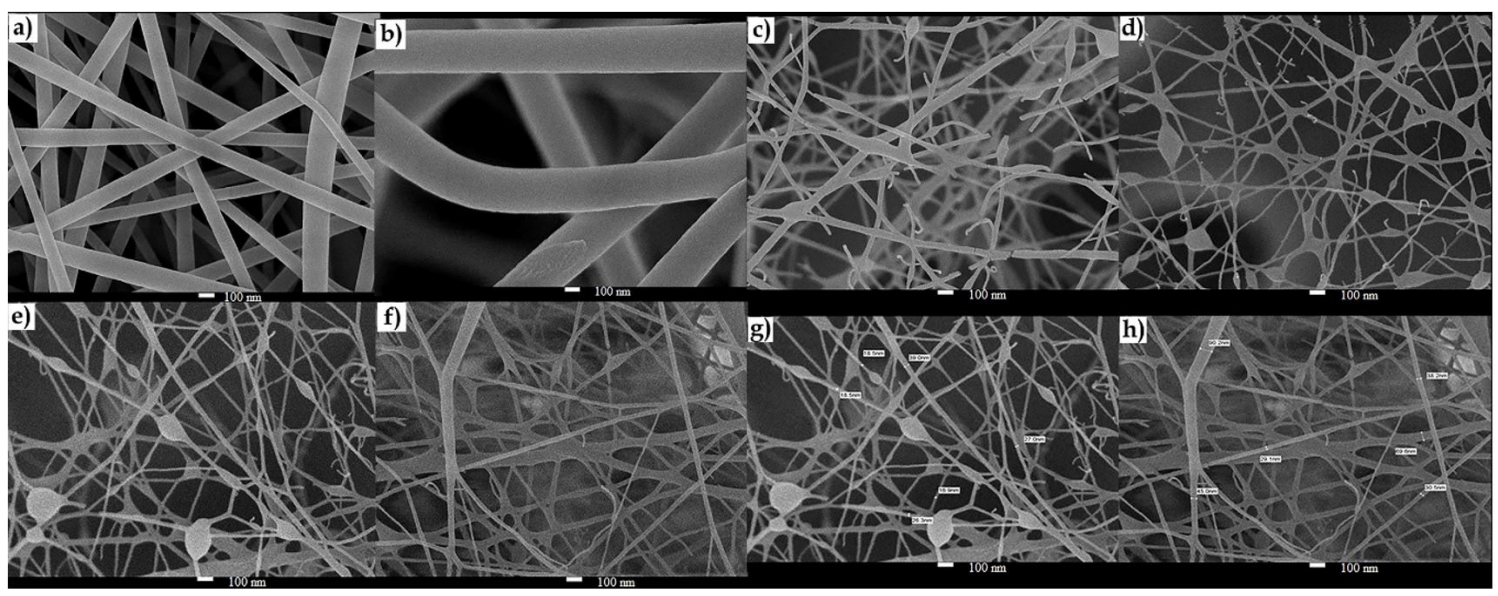

Figure 1. SEM images of (a) sample 1; (b) sample 2; (c) sample 3; (d) sample 4; (e) sample 5; (f) sample 6; (g) sample 7; (h) sample 8. 
of the nanofibers increased from 60 to $122 \mathrm{~nm}$ when the polymer concentration was increased from 10 to $16 \%$.

\subsection{FTIR analysis}

FTIR spectrum of 15 and $20 \% \mathrm{G}$ is presented in Figure 2a. As observed, there is a very slight peak at approximately $3300 \mathrm{~cm}^{-1}$ attributed to stretching vibration of amide group $(\mathrm{N}-\mathrm{H})$, as well as hydrogen bonding ${ }^{[24]}$. Following the signals that represent the digital fingerprint, such as the stretching vibration of: $\mathrm{C}=\mathrm{O}$ of primary amide, bending and stretching of $\mathrm{N}-\mathrm{H}$ of secondary amide and finally a bending of de N-H group at $1650 \mathrm{~cm}^{-1}, 1540 \mathrm{~cm}^{-1}$, and $1250 \mathrm{~cm}^{-1}$, respectively ${ }^{[38]}$.

\section{a}
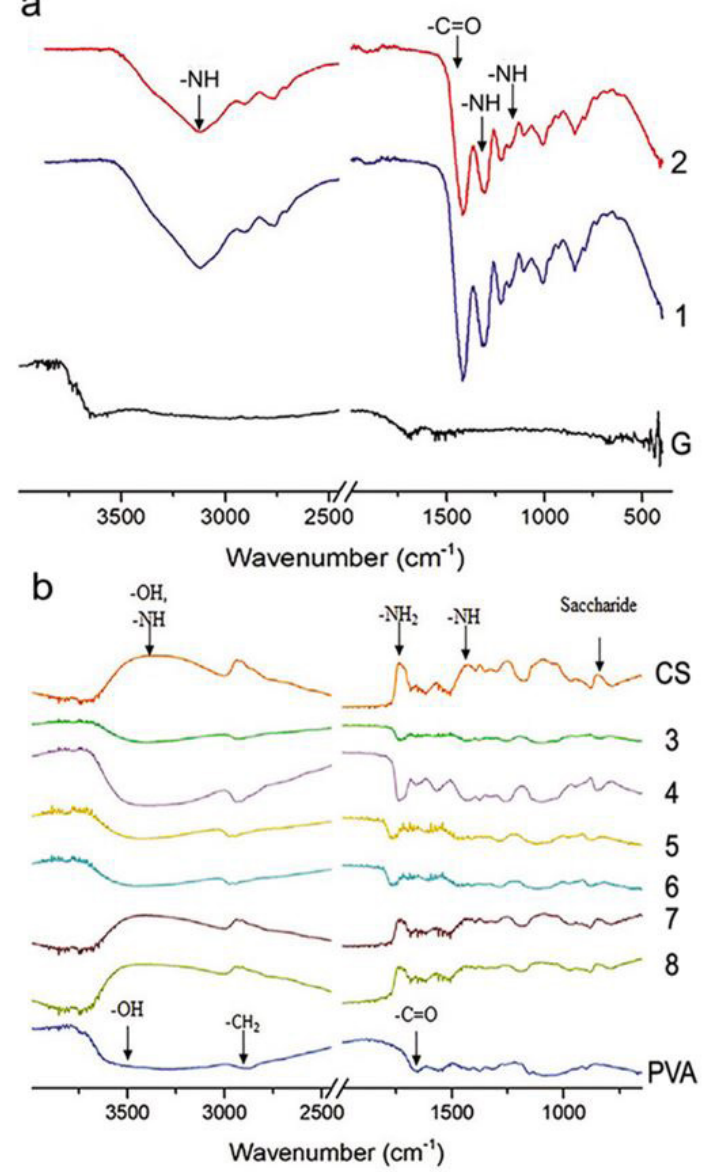

Figure 2. (a) FTIR spectra of G and samples 1 and 2; (b) FTIR spectra of CS-PVA nanofibers and neat CS and PVA.
FTIR spectrum of neat CS and PVA powder, as well as CS-PVA is presented in Figure $2 \mathrm{~b}$ as well. The FTIR spectra of neat CS showed the characteristic bands of the saccharide structure in the range of $880-1150 \mathrm{~cm}^{-1}[28]$, as well as the bands for amide I bending at $1660 \mathrm{~cm}^{-1}$ and amide II at $1560 \mathrm{~cm}^{-1}$, result of carbonyl stretching by the partial deacetylation of chitin ${ }^{[29,30]}$. The signal at $3455 \mathrm{~cm}^{-1}$ corresponds to $-\mathrm{NH}$ stretching is also present ${ }^{[31]}$; however, this band overlaps with the $-\mathrm{OH}$ vibrations ${ }^{[30]}$. Neat PVA spectra have three predominant signal: The band at $1760 \mathrm{~cm}^{-1}$ results of the $\mathrm{C}=\mathrm{O}$ stretching present on the PVA backbone ${ }^{[29]}$, the band at $2900 \mathrm{~cm}^{-1}$ for the $\mathrm{CH}_{2}$ asymmetric stretching vibration, and the band about $3500 \mathrm{~cm}^{-1}$ attributed to -OH is stretching ${ }^{[34]}$. In comparison with neat CS and neat PVA, CS-PVA presents a decrease in the wavenumber of the $-\mathrm{OH}$ and $-\mathrm{NH}$ signal. This behavior may be credited to the interactions between CS and PVA within the nanofiber system ${ }^{[30,33]}$. This interaction is by intermolecular and intramolecular hydrogen bonds through hydrophobic side chain aggregation, as represented by Alhosseini et al. ${ }^{[39]}$.

The presence of the amino and NAGA signals on the sample is evidence of its biodisponibility, which translates on the theoretical capability of them to carry their antimicrobial and therapeutic effects, by the interaction of the protonated -NH with the microorganism's cell walls ${ }^{[40]}$ and the stimulation of growth factors by the interaction between the NAGA present in CS and the NAGA receptors in macrophages ${ }^{[7]}$.

\subsection{DSC analysis}

DSC data for neat CS, neat PVA, and CS-PVA nanofibers are presented in Table 6. Neat CS presented one endothermic peak at $91.3^{\circ} \mathrm{C}$ and PVA an endothermic peak at $181.3^{\circ} \mathrm{C}$. However, the samples presented two endothermic peaks, a signal per compound, with a slight displacement of each temperature regarding the neat compounds. This effect denotes an interaction of the compounds, but also a non-miscibility between them. Therefore, it is important to differentiate the concepts of miscibility and interaction of the components. Miscibility is when a single-phase system is formed in a polymer-polymer blend, whereas an interaction is a chemical approach between chemical groups ${ }^{[37]}$.

\subsection{TGA analysis}

TGA thermograms of G and CS-PVA electrospun nanofibers are shown in Figure 3. In general terms, the thermal stability of gelatin electronspun fibers was fairly similar to gelatin powder. Beginning with sample $1(15 \%$ of $\mathrm{G})$, it presented a first weight loss at $50{ }^{\circ} \mathrm{C}$ to $100{ }^{\circ} \mathrm{C}$, which is most likely the result of moisture evaporation. However,

Table 6. Thermal characterization of neat CS and PVA and CS-PVA nanofibers.

\begin{tabular}{ccccc}
\hline Sample & $\begin{array}{c}\text { Melting Temperature } \\
\mathbf{C S}\left({ }^{\circ} \mathbf{C}\right)\end{array}$ & $\begin{array}{c}\text { Melting Temperature } \\
\text { PVA }\left({ }^{\circ} \mathbf{C}\right)\end{array}$ & $\begin{array}{c}\Delta \mathbf{H ~ C S} \\
(\mathbf{J} / \mathbf{g})\end{array}$ & $\begin{array}{c}\Delta \mathbf{H} \text { PVA } \\
(\mathbf{J} / \mathbf{g})\end{array}$ \\
\hline Neat & 91.3 & 181.3 & 350.8 & 102.9 \\
3 & 101.0 & 182.0 & 70.0 & 11.5 \\
4 & 82.9 & 185.1 & 67.0 & 15.0 \\
5 & 90.3 & 184.3 & 44.7 & 12.0 \\
6 & 84.1 & 185.1 & 83.2 & 12.8 \\
7 & 90.0 & 185.1 & 56.3 & 16.3 \\
8 & 92.4 & 185.9 & 60.9 & 18.5 \\
\hline
\end{tabular}


a)

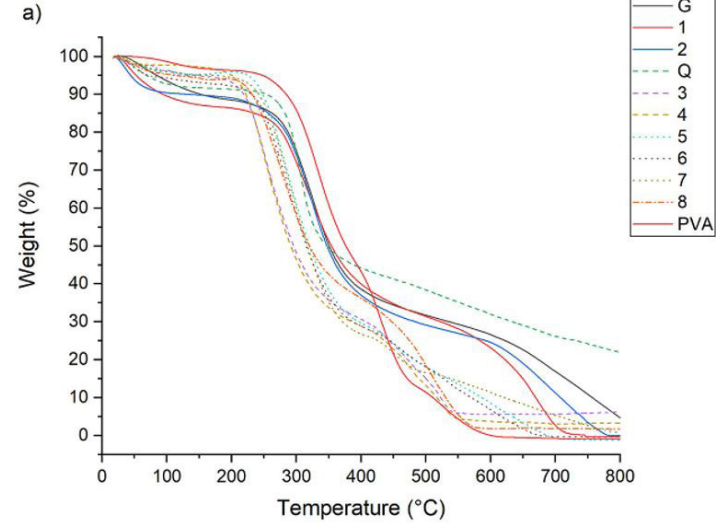

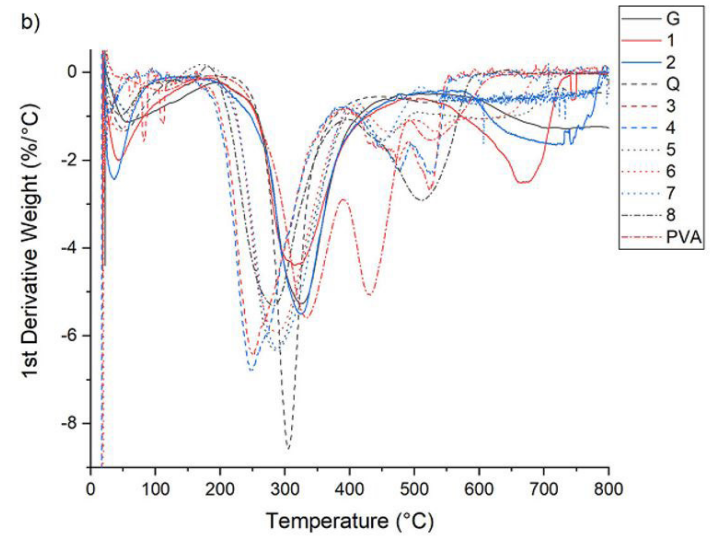

b)

Figure 3. Thermogravimetric curves of (a) TG and (b) DTG of G and CS-PVA nanofibers. G: gelatin, and PVA: polyvinyl alcohol.

around $330^{\circ} \mathrm{C}$ the maximum weight loss occurs, which is due to protein degradation ${ }^{[23]}$. At high temperatures, above $400{ }^{\circ} \mathrm{C}$ corresponds to the thermal decomposition of gelatin networks and molecular arrangements. The changes on thermal stability (maximum temperature) of gelatin samples were corroborated from DTG thermograms (Figure 3b). For CS-PVA samples, the samples showed a release of moisture around $100{ }^{\circ} \mathrm{C}$, although all of these presented a significant weight loss of approximately $80 \%$, from $210^{\circ} \mathrm{C}$ to $370{ }^{\circ} \mathrm{C}$. This loss mass is associated with amine unit, paired with $-\mathrm{CH}_{2} \mathrm{OH}$ group degradation ${ }^{[41]}$. As previously stated on DSC results, there is no apparent miscibility of the polymers, since the material present another twin degradation signal between $310^{\circ} \mathrm{C}$ and $420^{\circ} \mathrm{C}$, which is the characteristic of $\mathrm{PVA}^{[42]}$. It is due to polymer dehydration and by the formation of structures similar to polyacetylene. Moreover, during the thermal decomposition of PVA, it can release $\mathrm{CO} 2$ gas and to form oxides. CS showed the main degradation temperature between 280 to $375^{\circ} \mathrm{C}$, the DTG of Figure $3 \mathrm{~b}$ indicate that the maximum temperature of CS was $308^{\circ} \mathrm{C}$. Compared with materials, electrospun nanofibers of CS-PVA did not show an improvement on thermal stability. Nevertheless, it is important to emphasize that these results determine a very important part of possible application of these biomaterials. Since it can be observed that the nanofiber can withhold temperatures higher than $100{ }^{\circ} \mathrm{C}$, they can carry out as wound dressings as well as possibly be used as biomedical devices, since these materials generally do not involve a sterilization process with heating above $100^{\circ} \mathrm{C}$.

\subsection{Surface hydrophilicity}

The contact angle measurement result of water droplets on electrospun CS-PVA nanofiber surfaces are presented in Figure 4. The contact angle of all the nanofibers was found to be $<80^{\circ}$, which indicates the hydrophilic nature of the material. CS and PVA are hydrophilic materials, were CS hydrophilicity are due to the existence of - $\mathrm{NH}$ and -OH groups, as well as PVA hydrophilic nature, is due to its $-\mathrm{OH}$ groups ${ }^{[41,43]}$. Additionally, an inversely proportional behavior between PVA percentage and contact angle was observed, since at increasing PVA percentage

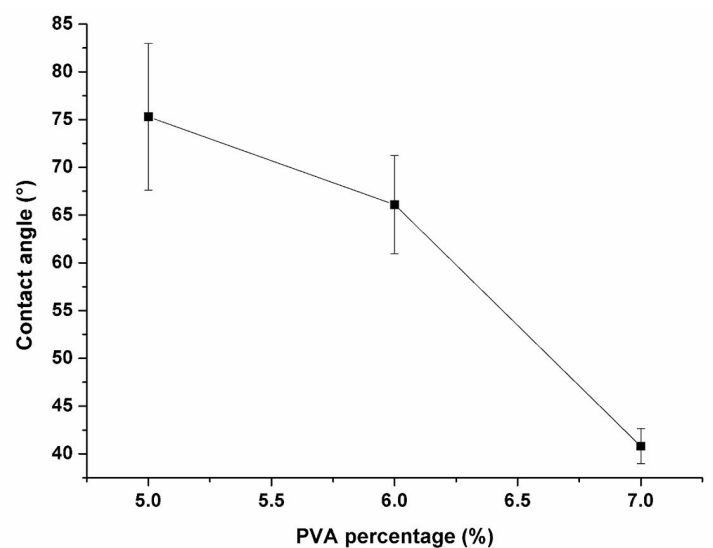

Figure 4. Contact angle for CS-PVA nanofibers.

in the nanofibers, a lower contact angle was obtained. This behavior is because of the hydrophilic nature of PVA explained before. This behavior was previously reported by Agrawal and Pramanik ${ }^{[4]}$. The importance of this analysis resides in the fact that, since the nanofiber mats would be for biomedical application. For this end, a hydrophilic material is desired, as previous studies have reported that materials with contact angles between 60 to $80^{\circ}$ enhance cell adhesion capability ${ }^{[39]}$, which is essential for the purpose of this work, that is to say, the application of electrospun CS-PVA nanofibers on diabetic skin ulcers.

\subsection{Antimicrobial analysis}

Antimicrobial photographs are shown on Figure 5 and Figure 6. With the purpose of screening the possible antimicrobial effect of the nanofibers, bacteria of Gram negative (S. typhi) and Gram positive (S. aureus) were assayed. It is important to point out that as today, there is no clear activity mechanism for the antimicrobial effect presented by chitosan, and instead, there have been different theories, which will be discussed next. Concerning to the discussion on chitosan and its possible activity mechanism upon S. typhi, Verlee et al. ${ }^{[45]}$, reported two mechanisms which share the characteristic of being developed upon the outer membrane of the bacteria, 

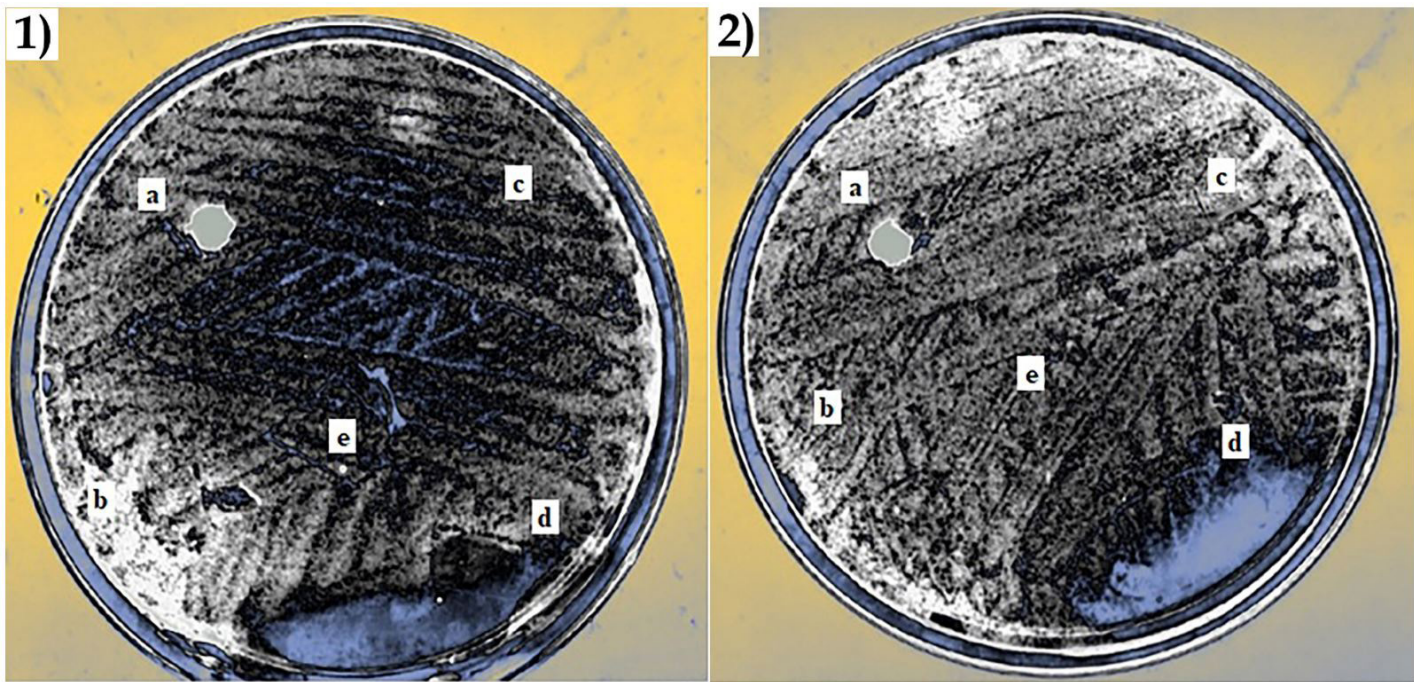

Figure 5. Antimicrobial assay of G and CS-PVA nanofibers against S. aureus. 1: (a) control; (b) sample 2; (c) sample 3; (d) sample 4; (e) sample 5. 2: (a) control; (b) sample 1; (c) sample 7; (d) sample 2; (e) sample 8.
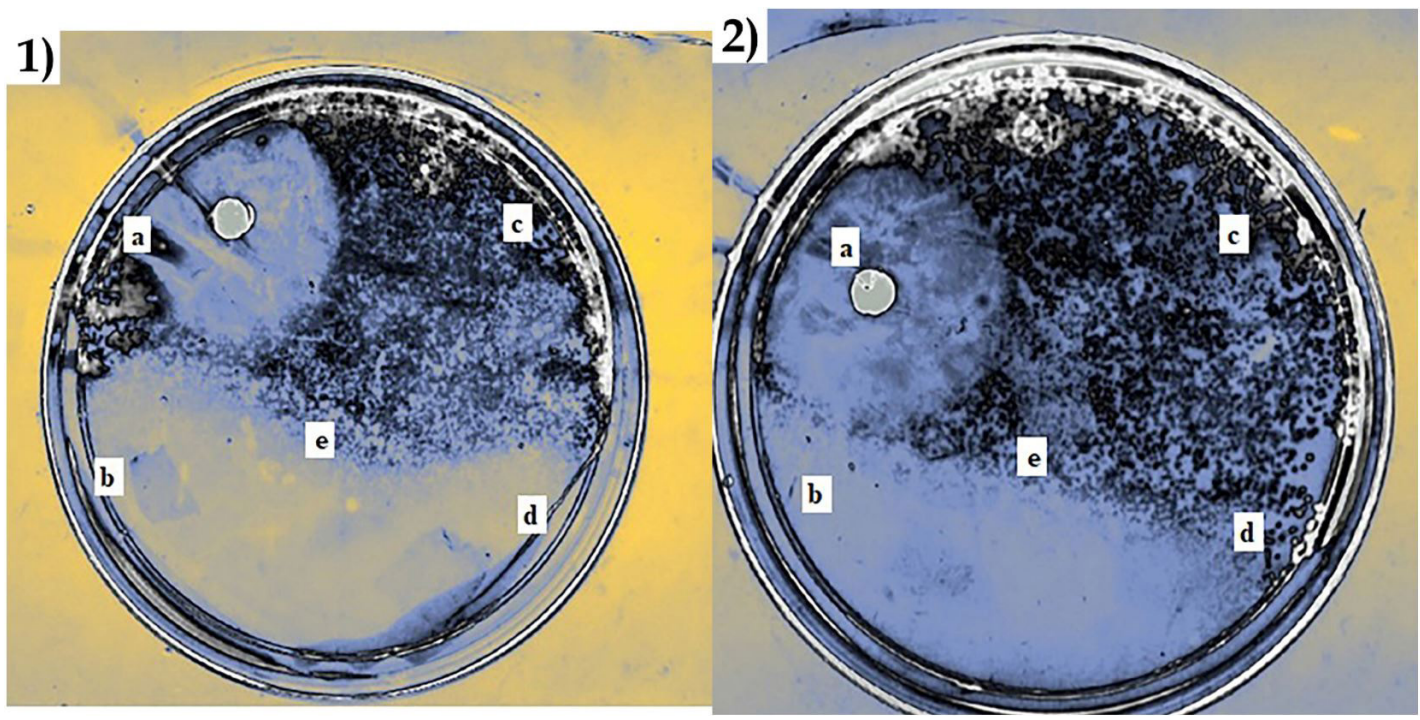

Figure 6. Antimicrobial assay of G and CS-PVA nanofibers against S. typhi. 1: (a) control; (b) sample 2; (c) sample 3; (d) sample 4; (e) sample 5. 2: (a) control; (b) sample 1; (c) sample 7; (d) sample 2; (e) sample 8.

chelation of cations $\left(\mathrm{Mg}^{2+}, \mathrm{Ca}^{2+} \text {, etc }\right)^{[46]}$ or electrostatic interaction of chitosan with the lipopolysaccharide present on the outer membrane (principal difference between gram negative and gram positive bacteria). Both effects result on a disruption of the inner membrane ${ }^{[43]}$, propitiating the intercellular material leaking. All these effects are attributed to the polycationic nature of $\mathrm{CS}$, since in acid media, the amino groups present on CS backbone get protonated. Since membrane configuration of Gram-positive bacteria differs from Gram negative bacteria (as mentioned above), chitosan action mechanism is said to also vary.

As observed on Figure 6, the sample of CS-PVA that presented the most activity was sample 6 and sample 1 for $\mathrm{G}$ nanofibers. In the case of these bacteria, such as
$S$. aureus, the membrane consists, among other things, of teichoic acids embedded into the cell surface. These acids are of the most important for bacterial physiology, since, they are responsible of controlling cationic concentration and enzyme activity, receptor and surfaces binding and protection against environmental stress ${ }^{[47]}$. According to Verlee et al. ${ }^{[45]}$, CS can establish electrostatic interactions with teichoic acids, compromising the bacteria physiology and resulting on antimicrobial activity. The samples that presented the better antimicrobial activity against $S$. typhi were also sample 6 for CS-PVA and sample 1 $(15 \% \mathrm{G})$. These effects agree with the expressed on the FTIR results, since there are amine group signals either in CS-PVA and G, and both were in acidic media, producing amino protonation. 


\section{Conclusions}

Nanofibers of gelatin and chitosan-polyvinyl alcohol were produced electrospinning process. The electrospun nanofibers produced showed a white color and did not showed chromatic differences between the samples. The gelatin nanofibers showed higher thickness in comparison to CS-PVA nanofibers, it is attributed to complex structure of this biopolymer. The elongation at break of CS-PVA samples is directly related to PVA content. The morphological analysis of gelatin nanofibers and sample 6 showed a homogeneous fibrillar formation. Particular structural and thermal characteristics of the samples were identified by infrared and thermal analysis. The contact angles developed by the samples would be suitable for biomedical applications. The sample that showed the best antimicrobial activity against S. thyphi. This sample is capable of integrating with typical small molecules (bioactive compounds) or grow factors to provide a sustained release behavior for an application on chronic patients of diabetes.

\section{Acknowledgements}

MSc. Campa Siqueiros want to thank you for financial support provided by Consejo Nacional de Ciencia y Tecnología (CONACyT). The authors would like to thank to Laboratorio Nacional de Nano y Biomateriales (LANNBIO) at CINVESTAV-IPN. Unidad Mérida (under projects FOMIX-Yucatán 2008-108160, CONACYT LAB-2009-01123913, 292692, 294643, and 299083) and Laboratorio de Microbiología Molecular y Aplicada at ITMérida, for the facilities to carry out this research.

\section{References}

1. Zarrintaj, P., Moghaddam, A. S., Manouchehri, S., Atoufi, Z., Amiri, A., Amirkhani, M. A., Nilforoushzadeh, M. A., Saeb, M. R., Hamblin, M. R., \& Mozafari, M. (2017). Can regenerative medicine and nanotechnology combine to heal wounds? The search for the ideal wound dressing. Nanomedicine, 12(19), 2403-2422. http://dx.doi.org/10.2217/nnm-2017-0173. PMid:28868968.

2. Escárcega-Galaz, A. A., Cruz-Mercado, J. L. D. L., LópezCervantes, J., Sánchez-Machado, D. I., Brito-Zurita, O. R., \& Ornelas-Aguirre, J. M. (2018). Chitosan treatment for skin ulcers associated with diabetes. Saudi Journal of Biological Sciences, 25(1), 130-135. http://dx.doi.org/10.1016/j.sjbs.2017.03.017. PMid:29379369.

3. Liu, H., Chenyu, W., Chen, L., Yanguo, Q., Zhonghan, W., Fan, Y., Zuhao, L., \& Jincheng, W. (2018). A functional chitosanbased hydrogel as a wound dress and in drug delivery system in the treatment of wound healing. Royal Society of Chemistry Advances, 8(14), 7533-7549. http://dx.doi.org/10.1039/ C7RA13510F.

4. Hu, J., Song, Y., Zhang, C., Huang, W., Chen, A., He, H., Zhang, S., Chen, Y., Tu, C., Liu, J., Xuan, X., Chang, Y., Zheng, J., \& Wu, J. (2020). Highly aligned electrospun collagen/polycaprolactone surgical sutures with sustained release of growth factors for wound regeneration. ACS Applied Bio Materials, 3(2), 965976. http://dx.doi.org/10.1021/acsabm.9b01000.

5. Moura, L. I., Días, A., Carvalho, E., \& De Sousa, H. (2013). Recent advances on the development of wound dressings for diabetic foot ulcer treatment: a review. Acta Biomaterialia, 9(7),
7093-7114. http://dx.doi.org/10.1016/j.actbio.2013.03.033. PMid:23542233.

6. Tellechea, A., Leal, E., Veves, A., \& Carvalho, E. (2009). Inflammatory and angiogenic abnormalities in diabetic wound healing: role of neuropeptides and therapeutic perspectives. The Open Circulation \& Vascular Journal, 3(1), 43-55. http:// dx.doi.org/10.2174/1874382601003010043.

7. Periayah, M. H., Halim, A. S., Saad, A. Z., Yaacob, N. S., Hussein, A. R., Karim, F. A., Rashid, A. H., \& Ujang, Z. (2015). Chitosan scaffold enhances growth factor release in wound healing in Von Willebrand disease. International Journal of Clinical and Experimental Medicine, 8(9), 15611-15620. PMid:26629055.

8. Rinaudo, M. (2011). Chitin and chitosan: properties and applications. Progress in Polymer Science, 38(7), 603-632. http://dx.doi.org/10.1016/j.progpolymsci.2006.06.001.

9. Raafat, D., Von Bargen, K., Haas, A., \& Sahl, H.-G. (2008). Insights into the mode if action of chitosan as an antibacterial compound. Applied and Environmental Microbiology, 74(12), 3764-3773. http://dx.doi.org/10.1128/AEM.00453-08. PMid: 18456858.

10. Li, Z., Yang, X., Song, X., Ma, H., \& Zhang, P. (2016). Chitosan oligosaccharide reduces propofol requirements and propofolrelated side effects. Marine Drugs, 14(12), 234. http://dx.doi. org/10.3390/md14120234. PMid:28009824.

11. Mohebbi, S., Nezhad, M. N., Zarrintaj, P., Jafari, S. H., Gholizadeh, S. S., Saeb, M. R., \& Mozafari, M. (2019). Chitosan in biomedical engineering: a critical review. Current Stem Cell Research \& Therapy, 14(2), 93-116. http://dx.doi.or g/10.2174/1574888X13666180912142028. PMid:30207244.

12. Ueno, H., Nakamura, F., Murakami, M., Okumura, M., Kadosawa, T., \& Fujinaga, T. (2001). Evaluation effects of chitosan for the extracellular matrix production by fibroblasts and the growth factors production by macrophages. Biomaterials, 22(15), 2125-2130. http://dx.doi.org/10.1016/S0142-9612(00)00401-4. PMid:11432592.

13. Howling, G. I., Dettmar, P. W., Goddard, P. A., Hampson, F. C., Dornish, M., \& Wood, E. J. (2001). The effect of chitin and chitosan on the proliferation of human skin fibroblasts and keratinocytes in vitro. Biomaterials, 22(22), 2959-2966. http:// dx.doi.org/10.1016/S0142-9612(01)00042-4. PMid:11575470.

14. Sandri, G., Rossi, S., Bonferoni, M. C., Caramella, C., \& Ferrari, F. (2020). Electrospinning technologies in wound dressing applications. In J. Boateng (Ed.), Therapeutic dressings and wound healing applications (1st ed., pp. 315-336). Hoboken: Wiley. http://dx.doi.org/10.1002/9781119433316.ch14.

15. Ramakrishna, S., Fujihara, K., Teo, W. E., Lim, T. C., \& Ma, Z. (2005). An introduction to electrospinning and nanofibers. Singapur: World Scientific Publishing.

16. Wang, L., Yang, H., Hou, J., Zhang, W., Xiang, C., \& Li, L. (2017). Effect of the electrical conductivity of core solutions on the morphology and structure of core-shell CA-PCL/CS Nanofibers. New Journal of Chemistry, 41(24), 15072-15078. http://dx.doi.org/10.1039/C7NJ02805A.

17. Khajavi, R., \& Abbasipour, M. (2012). Electrospinning as a versatile method for fabricating core/shell, hollow and porous nanofibers. Scientia Iranica, 19(6), 2029-2034. http://dx.doi. org/10.1016/j.scient.2012.10.037.

18. Bonzani, I., George, J., \& Stevens, M. (2006). Novel materials for bone and cartilage regeneration. Current Opinion in Chemical Biology, 10(6), 568-575. http://dx.doi.org/10.1016/j. cbpa.2006.09.009. PMid:17011226.

19. Baker, B. M., Gee, A. O., Metter, R. B., Nathan, A. S., Marklein, R. A., Burdick, J. A., \& Mauck, R. L. (2008). The potential to improve cell infiltration in composite fiber-aligned electrospun scaffolds by the selective removal of sacrificial fibers. 
Biomaterials, 29(15), 2348-2358. http://dx.doi.org/10.1016/j. biomaterials.2008.01.032. PMid:18313138.

20. Kenawy, R., Bowlin, G. L., Mansfield, K., Layman, J., Simpson, D. G., Sanders, E. H., \& Wnek, G. E. (2002). Release of tetracycline hydrochloride from electrospun poly(ethyleneco-vinyl acetate), poly(lactic acid), and a blend. Journal of Controlled Release, 81(1-2), 57-64. http://dx.doi.org/10.1016/ S0168-3659(02)00041-X. PMid:11992678.

21. Bagheri, B., Zarrintaj, P., Samadi, A., Zarrintaj, R., Ganjali, M. R., Saeb, M. R., Mozafari, M., Park, O. O., \& Kim, Y. C. (2020). Tissue engineering with electrospun electro-responsive chitosan-aniline oligomer/polyvinyl alcohol. International Journal of Biological Macromolecules, 147, 160-169. http:// dx.doi.org/10.1016/j.ijbiomac.2019.12.264. PMid:31904459.

22. Boateng, J., \& Catanzano, O. (2015). Advanced therapeutic dressings for effective wound healing: a review. Journal of Pharmaceutical Sciences, 104(11), 3653-3680. http://dx.doi. org/10.1002/jps.24610. PMid:26308473.

23. Kotatha, D., Hirata, M., Ogino, M., Uchida, S., Ishikawa, M., Furuike, T., \& Tamura, H. (2019). Preparation and characterization of electrospun gelatin nanofibers for use as nonaqueous electrolyte in electric double-layer capacitor. Journal of Nanotechnology, 10, 1-11. http://dx.doi.org/10.1155/2019/2501039.

24. Aramwit, P., Jaichawa, N., Ratanavaraporn, J., \& Srichana, T. (2015). A comparative study of type A and type B gelatin nanoparticles as the controlled release carriers for different model compounds. Materials Express, 5(3), 241-248. http:// dx.doi.org/10.1166/mex.2015.1233.

25. Wang, X., Ding, B., \& Li, B. (2013). Biomimetic electrospun nanofibrous structures for tissue engineering. Materials Today, 16(6), 229-241. http://dx.doi.org/10.1016/j.mattod.2013.06.005. PMid:25125992.

26. Kriegel, C., Kit, K. M., McClements, D. J., \& Weiss, J. (2009). Electrospinning of chitosan-poly(ethylene oxide) blend nanofibers in the presence of micellar surfactant solutions. Polymer, 50(1), 189-200. http://dx.doi.org/10.1016/j.polymer.2008.09.041.

27. Chen, J. P., Chang, G. Y., \& Chen, J. K. (2008). Electrospun collagen/chitosan nanofibrous membrane as wound dressing. Colloids and Surfaces A, Physicochemical and Engineering Aspects, 313, 183-188. http://dx.doi.org/10.1016/j.colsurfa.2007.04.129.

28. Chong, E. J., Phan, T. T., Lim, I. J., Zhang, Y. Z., Bay, B. H., Ramakrishna, S., \& Lim, C. T. (2007). Evaluation of electrospun $\mathrm{PCL} /$ gelatin nanofibrous scaffold for wound healing and layered dermal reconstitution. Acta Biomaterialia, 3(3), 321-330. http:// dx.doi.org/10.1016/j.actbio.2007.01.002. PMid:17321811.

29. Yousefi, A., Aliyeh, H. Z., Khorasani, S. N., \& Abdolmaleki, A. (2017). Optimization and characterization of electrospun chitosan/poly(vinyl alcohol) nanofibers as a phenol adsorbent via response surface methodology: optimization of Cs/PVA electrospun nanofibers as adsorbent via RSM. Polymers for Advanced Technologies, 28(12), 1872-1878. http://dx.doi. org/10.1002/pat.4075.

30. Alavarse, A. C., Waitman, F., Colque, J. T., Moura da Silva, V., Prieto, T., Venancio, E. C., \& Bonvent, J. J. (2017). Tetracycline hydrochloride-loaded electrospun nanofibers mats based on PVA and chitosan for wound dressing. Materials Science and Engineering C, 77, 271-281. http://dx.doi.org/10.1016/j. msec.2017.03.199. PMid:28532030.

31. Okutan, N., Terzi, P., \& Altay, F. (2014). Affecting parameters on electrospinning process and characterization of electrospun gelatin nanofibers. Food Hydrocolloids, 39, 19-26. http:// dx.doi.org/10.1016/j.foodhyd.2013.12.022.

32. Ruiz-Ruiz, J. C., Ramon-Sierra, J. M., Arias-Argaez, C., Magaña-Ortiz, D., \& Ortiz-Vázquez, E. (2017). Antibacterial activity of proteins extracted from the pulp of wild edible fruit of Bromelia pinguin L. International Journal of Food Properties, 20(1), 220-230. http://dx.doi.org/10.1080/10942 912.2016.1154572.

33. Horsfall, G. A. (1982). Factors influencing the daylight photodegradation of Nylon. Textile Research Journal, 52(3), 197-205. http://dx.doi.org/10.1177/004051758205200307.

34. Retting, M. K., \& Ah-Hen, K. (2014). El color de los alimentos un criterio de calidad medible. Agro Sur, 42(2), 2-7. http:// dx.doi.org/10.4206/agrosur.2014.v42n2-07.

35. Maskan, M. (2001). Kinetics of color change of kiwifruits during hot air and microwave drying. Journal of Food Engineering, 48(2), 169-175. http://dx.doi.org/10.1016/S02608774(00)00154-0.

36. Duconseille, A., Astruc, T., Quintana, N., Meersman, F., \& Sante-Lhoutellier, V. (2015). Gelatin structure and composition linked to hard capsule dissolution: a review. Food Hydrocolloids, 43,360-376. http://dx.doi.org/10.1016/j.foodhyd.2014.06.006.

37. Tarus, B., Fadel, N.,Al-Oufy, A., \& El-Messiry, M. (2016). Effect of polymer concentration on the morphology and mechanical characteristics of electrospun cellulose acetate and poly (vinyl chloride) nanofiber mats. Alexandria Engineering Journal, 55(3), 2975-2984. http://dx.doi.org/10.1016/j.aej.2016.04.025.

38. Ji, L., Qiao, W., Zhang, Y., Wu, H., Miao, S., Cheng, Z., Gong, Q., Liang, J., \& Zhu, A. (2017). A gelatin composite scaffold strengthened by drug-loaded halloysite nanotubes. Materials Science and Engineering C, 78, 362-369. http:// dx.doi.org/10.1016/j.msec.2017.04.070. PMid:28575996.

39. Alhosseini, S. N., Moztarzadeh, F., Mozafari, M., Asgari, S., Dodel, M., Samadikuchaksaraei, A., Kargozar, S., \& Jalali, N. (2012). Synthesis and characterization of electrospun polyvinyl alcohol nanofibrous scaffolds modified by blending with chitosan for neural tissue engineering. International Journal of Nanomedicine, 7, 25-34. http://dx.doi.org/10.2147/IJN. S25376. PMid:22275820.

40. Martínez-Camacho, A. P., Cortez-Rocha, M. O., GracianoVerdugo, A. Z., Rodríguez-Félix, F., Castillo-Ortega, M. M., Burgos-Hernández, A., Ezquerra-Brauer, J. M., \& PlascenciaJatomea, M. (2013). Extruded films of blended chitosan, low density polyethylene and ethylene acrylic acid. Carbohydrate Polymers, 91(2), 666-674. http://dx.doi.org/10.1016/j. carbpol.2012.08.076. PMid:23121962.

41. Bonilla, J., Fortunati, E., Atarés, L., Chiralt, A., \& Kenny, J. M. (2014). Physical, structural and antimicrobial properties of poly vinyl alcohol-chitosan biodegradable films. Food Hydrocolloids, 35, 463-470. http://dx.doi.org/10.1016/j. foodhyd.2013.07.002.

42. Çay, A., Miraftab, M., \& Kumbasar, E. P. A. (2014). Characterization and swelling performance of physically stabilized electrospun poly(vinyl alcohol)/chitosan nanofibers. European Polymer Journal, 61, 253-262. http://dx.doi. org/10.1016/j.eurpolymj.2014.10.017.

43. Liu, H., Du, Y., Wang, X., \& Sun, L. (2004). Chitosan kills bacteria through cell membrane damage. International Journal of Food Microbiology, 95(2), 147-155. http://dx.doi. org/10.1016/j.ijfoodmicro.2004.01.022. PMid:15282127.

44. Agrawal, P., \& Pramanik, K. (2016). Chitosan-poly(vinyl alcohol) nanofibers by free surface electrospinning for tissue engineering applications. Journal of Tissue Engineering and Regenerative Medicine, 13(5), 485-497. http://dx.doi. org/10.1007/s13770-016-9092-3. PMid:30603430.

45. Verlee, A., Mincke, S., \& Stevens, C. V. (2017). Recent developments in antibacterial and antifungal chitosan and its derivatives. Carbohydrate Polymers, 164, 268-283. http:// dx.doi.org/10.1016/j.carbpol.2017.02.001. PMid:28325326. 
46. Goy, R. C., Britto, D. D., \& Assis, O. B. G. (2009). A review of the antimicrobial activity of chitosan. Polimeros: Ciência e Tecnologia, 19(3), 241-247. http://dx.doi.org/10.1590/S010414282009000300013.

47. Xia, G., Kohler, T., \& Peschel, A. (2010). The wall teichoic acid and lipoteichoic acid polymers of Staphylococcus aureus. International Journal of Medical Microbiology, 300(2-3),
148-154. http://dx.doi.org/10.1016/j.ijmm.2009.10.001. PMid:19896895.

Received: Feb. 04, 2020

Revised: Apr. 13, 2020

Accepted: Apr. 14, 2020 